\title{
Purification, Characterization, and Antioxidant Activity of Daucosterol and Stigmasterol from Prangos ferulacea
}

\author{
Hossein Abdollahnezhad ${ }^{1 \mathbb{D}}$, Mir Babak Bahadori ${ }^{2, *}{ }^{(\mathbb{D})}$, Hadi Pourjafar ${ }^{3,4} \mathbb{( D}$, Nasrin Movahhedin 1 (i) \\ Department of Pharmacognosy, Faculty of Pharmacy, Urmia University of Medical Sciences, Urmia, Iran \\ Medicinal Plants Research Center, Maragheh University of Medical Sciences, Maragheh, Iran \\ Department of Food Sciences and nutrition, Maragheh University of Medical Sciences, Maragheh, Iran \\ 4 Alborz University of Medical Sciences, Dietary supplements and Probiotic Research Center, Karaj, Iran \\ * Correspondence: mb.bahadori@gmail.com
}

Scopus Author ID 57217797462

Received: 28.09.2020; Revised: 20.10.2020; Accepted: 22.10.2020; Published: 25.10.2020

\begin{abstract}
The genus Prangos is traditionally used for medicinal and food purposes. This genus contains a wide range of bioactive metabolites. In this work, phytochemical investigation and antioxidant activity evaluation of Prangos ferulacea were carried out. Chromatographic techniques were employed for the purification of extracts components. Spectroscopic techniques such as NMR, FT-IR, together with elemental analysis, were used for the structure elucidation of isolated compounds. Stigmasterol, daucosterol, and salicylic acid were purified and identified. Isolated compounds showed moderate to high antiradical activity in DPPH antioxidant assay. Results indicated the potential of P. ferulacea as a source of steroid and their glycosides and also its possible applications as antioxidant agents.
\end{abstract}

Keywords: Prangos; phytochemistry; stigmasterol; daucosterol; antioxidant.

(C) 2020 by the authors. This article is an open-access article distributed under the terms and conditions of the Creative Commons Attribution (CC BY) license (https://creativecommons.org/licenses/by/4.0/).

\section{Introduction}

The genus Prangos L. is belongs to the Apioideae subfamily of the Apiaceae family, including about 72 herbaceous hemicryptophyte species in the world [1]. Most members of the genus are distributed in central and southeast Asia. Prangos has 15 species in Iran, of which 5 species are endemic to the country [2].

The genus has traditional uses such as fodder, food, spice, and instead of chemical drugs for the treatment of some diseases and health problems like seizures, bleeding, headache, leukoplakia, and digestive disorders [3-5]. The genus exerts several pharmacological effects such as a diuretic, antiflatulent, abortifacient, anti-hemorrhoid, anti-inflammatory, antispasmodic, anthelmintic, emollient, carminative, and tonic [6-8]. Furthermore, modern studies have shown some biological properties, including cytotoxic, allelopathic, antibacterial, antioxidant, and antifungal activities [9, 10]. Prangos species contain a large number of coumarin compounds, of which osthol, oxypeucedanin, and isoimperatorin are the most famous. In addition, terpenoids, alkaloids, and flavonoids have been reported from this genus [11-13]. Volatile compounds of the genus have important biological activities, too, such as antioxidant, antidiabetic, anti-Alzheimer's, skin-care, and insecticidal effects $[14,15]$. The most abundant volatiles of the genus is $\alpha$-pinene, $\beta$-pinene, carene, $\beta$-phellandrene, and $\alpha$ bisabolol [16]. Besides biological properties, the chemical composition of essential oils is important for the classification of species in chemotaxonomic studies [17]. 
The local people use the oily exudate from freshly cut roots of $P$. ferulacea as a topical cream for wound healing agents [18]. Also, according to our observation, people apply sodden of dried leaves of P. ferulacea as anti-worm medicine for human and livestock at Kanizard, Grdaseh, and Snjaleh villages, Piranshahr, West Azerbaijan province, Iran. The local name of $P$. ferulacea is Halz in Kurdish, and it is called Jasher in Persian.

At the present work, we aimed to evaluate the chemical composition of P. ferulacea from West Azerbaijan for the first time. Also, radical scavenging properties of isolated natural products were estimated using the DPPH assay.

\section{Materials and Methods}

\subsection{Chemicals and reagents.}

The solvents were provided by Carlo Erba (Italy) and Daejung (South Korea). Silica gel for column chromatography and TLC Silica gel were purchased from Merck (Germany).

\subsection{Plant material.}

Fresh leaves and stems were collected in June 2015 from the mountains of Kanizard village, Piranshahr, West Azerbaijan province, Iran. Taxonomic identification of plant was performed by Mr. Shahram Bahadori at the herbarium of Faculty of Pharmacy, Urmia University of Medical Sciences, Urmia, Iran.

\subsection{Preparation of extracts.}

The extracts were achieved from aerial parts of $P$. ferulacea by the maceration method. For this, $750 \mathrm{~g}$ of powdered material was extracted by $3 \mathrm{~L}$ of $n$-hexane, dichloromethane, ethyl acetate, and methanol consecutively. The extraction was performed using a magnetic shaker at room temperature for $48 \mathrm{~h}$. The extracts were filtered by a paper filter, and solutions were concentrated by a rotary vacuum evaporator at $40^{\circ} \mathrm{C}$ until obtaining crude dry extracts [19].

\subsection{Purification of metabolites.}

The ethyl acetate extract ( $8.8 \mathrm{~g}$ ) was fractionated by a vacuum liquid chromatography (VLC) (silica gel 70-230 mesh), eluted with hexane- $\mathrm{CH}_{2} \mathrm{Cl}_{2}(10: 0,7: 3,1: 1,3: 7,0: 10)$ and $\mathrm{CH}_{2} \mathrm{Cl}_{2}-\mathrm{MeOH}(7: 3,1: 1,3: 7,0: 10)$ and $\mathrm{MeOH}$-acetone $(7: 3,1: 1,3: 7,0: 10)$ to obtain 13 fractions (F1-F13). All fractions were monitored by TLC, and then similar fractions were combined. The new fraction $\mathrm{F}_{34}(2.57 \mathrm{~g}$, obtained from the combination of $\mathrm{F} 3$ and $\mathrm{F} 4)$ was loaded on four preparative TLC plates (silica gel $60 \mathrm{Gf}_{254}$ ) and eluted by $\mathrm{CHCl}_{3}$-hexane (4:1) which afforded 2 fluorescent lines which were crushed from plates and washed by methanol and ethyl acetate. The result was two pure compounds, $1(11 \mathrm{mg})$ and $2(18 \mathrm{mg}) . \mathrm{F}_{567}(3.37 \mathrm{~g}$, obtained from the combination of F5-F7) was separated by silica gel column chromatography eluted by $\mathrm{CHCl}_{3}-\mathrm{MeOH}(100: 0,98: 2,95: 5,90: 10,80: 20,0: 100)$ to obtain 10 sub-fractions. After solvent evaporation of fractions at room temperature, cubic and white crystals were obtained from fraction 10 (compound 3, $20 \mathrm{mg}$ ). 
2.5. NMR experiments.

NMR spectrum was obtained by recording on Bruker Avance $400 \mathrm{MHz}$ spectrometer (Germany), acting at $400 \mathrm{MHz}$ for ${ }^{1} \mathrm{H}$ and $100 \mathrm{MHz}$ for ${ }^{13} \mathrm{C}$. DMSO-d6 and $\mathrm{CDCl}_{3}$ were applied as deuterated solvents and TMS as an internal standard.

\subsection{FT-IR analysis.}

IR spectrum was recorded on a Shimadzu FTIR-8400S spectrophotometer (Japan) operating $\mathrm{KBr}$ pellets.

\subsection{Melting point.}

Measurement of melting points was done in open glass capillaries using the Electrothermal melting point apparatus.

\subsection{Elemental analysis.}

The elemental analysis for $\mathrm{C}, \mathrm{N}$, and $\mathrm{H}$ atoms was performed by using the Costech elemental analyzer [20].

\subsection{Antioxidant activity assessment.}

DPPH (2,2-Diphenyl-1-picrylhydrazyl), which has $\mathrm{C}_{18} \mathrm{H}_{12} \mathrm{~N}_{5} \mathrm{O}_{6}$ molecular formula, was used to estimate the antioxidant properties of obtained compounds (Fluka Chemie AG, Bucks). As the reference compound, rutin was used. Several concentrations of isolated compounds (solved in methanol) were provided (7.8-500 $\mu \mathrm{g} / \mathrm{mL}$ ). Eight milligrams of DPPH was dissolved in methanol to achieve a stock with a concentration of $80 \mu \mathrm{g} / \mathrm{mL}$. DPPH $(1 \mathrm{~mL})$ was added to dilute solutions $(1 \mathrm{~mL})$ and maintained $30 \mathrm{~min}$ for any reaction to occur. The UV absorbance was recorded at $517 \mathrm{~nm}$ [21]. The experiments were performed in triplicate, and the average absorption was recorded for each concentration. $\mathrm{IC}_{50}$ values were calculated and expressed as mean \pm SD [22].

\section{Results and Discussion}

The ethyl acetate extract of the aerial parts of $P$. ferulacea was subjected to vacuum liquid chromatography, column chromatography, and also preparative thin layer chromatography to yield compounds $\mathbf{1 - 3}$. The structure elucidation of purified compounds was performed using ${ }^{13} \mathrm{C}$ NMR, ${ }^{1} \mathrm{H}$ NMR, and FT-IR spectra as well as elemental analysis. The obtained data were compared with those of the literature and were confirmed. Compound 1 was identified as a glycoside sterol due to its characteristic signals in NMR spectra. Elemental analysis showed the molecular formula of $\mathrm{C}_{35} \mathrm{H}_{60} \mathrm{O}_{6}$, which is in accordance with a sterol aglycone and a six-carbon glycoside. IR spectra confirmed the presence of $\mathrm{OH}$ groups, olefinic hydrogen, and the C-O bond. Finally, the structure of 3-O-Gly- $\beta$-sitosterol, also called daucosterol, was determined for this compound [23]. The melting point of compound 1 was measured as $274-276^{\circ} \mathrm{C}$, which is in accordance with those reported for daucosterol in the literature (Figure 1). This is the first report of daucosterol from the genus Prangos. It has wide pharmacological activities such as antimicrobial, neuroprotective, and anticoagulant [24]. In recent years, there is a focus on the evaluation of its anticancer potential. 


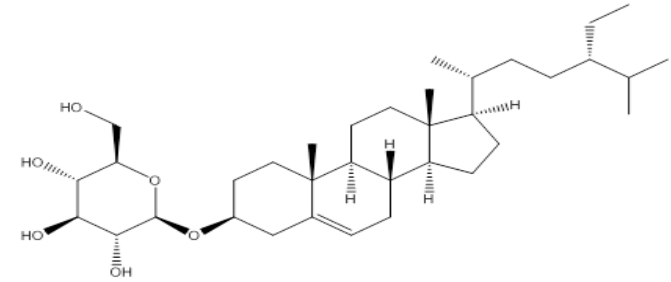

Figure 1. Chemical structure of daucosterol.

Compound 2 was identified as a phytosterol. Except for the glycoside region, it has a similar pattern in NMR signals with compound $\mathbf{1}$. The presence of four olefinic carbon signals, and characteristic methyl groups of sterols in ${ }^{1} \mathrm{H}$ NMR, revealed that its chemical structure is a phytosterol with 29 carbon atoms, of which four atoms are involved in carbon-carbon double bonds. A comparison of obtained spectra with related herbal compounds showed that compound 2 could be stigmasterol. IR results, together with elemental analysis $\left(\mathrm{C}_{29} \mathrm{H}_{48} \mathrm{O}\right)$, confirmed the structure of stigmasterol (Figure 2). Moreover, its melting point (161-164.5 ${ }^{\circ} \mathrm{C}$ ) was obtained similar to previous works which reported the isolation of stigmasterol from natural sources $[25,26]$. To the best of our knowledge, this is the first time that stigmasterol is isolated from Prangos members. Stigmasterol has hypoglycemic, hypolipidemic, antibacterial, and memory-enhancing effects [27].

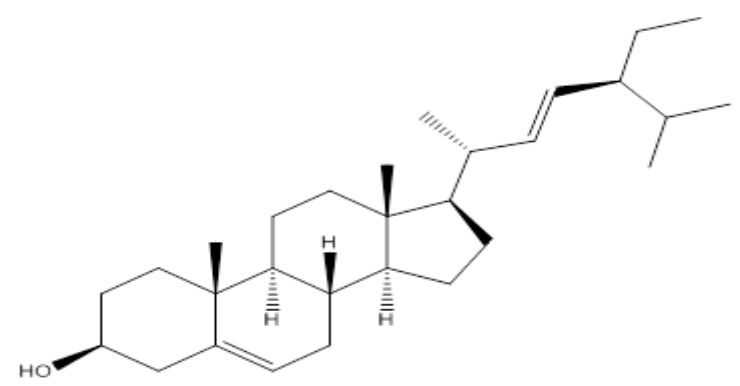

Figure 2. Chemical structure of stigmasterol.

Compound 3 has a simple ${ }^{13} \mathrm{C}$ NMR spectrum, including 6 aromatic carbons and one ketone signal. Also, ${ }^{1} \mathrm{H}$ NMR spectrum showed the presence of 4 aromatic protons together with one carboxylic acid proton. These data, in combination with elemental analysis $\left(\mathrm{C}_{7} \mathrm{H}_{6} \mathrm{O}_{3}\right)$ and melting point determination $\left(157-158.5^{\circ} \mathrm{C}\right)$, led to salicylic acid structure for compound 3 (Figure 3). Salicylic acid has important biological properties such as pain killer, antiinflammatory, and antifungal [28]. Moreover, it is the starting agent for the synthesis of Aspirin.

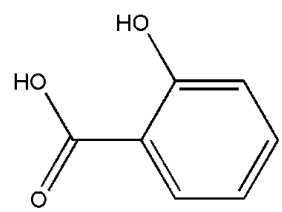

Figure 3. Chemical structure of salicylic acid.

Isolated compounds were also investigated for their radical scavenging activities through DPPH assay. Radical scavenging ability is a very important mechanism of antioxidant activity [29]. Purified compounds in this study, found to have moderate to strong antioxidant potential. Salicylic acid exerted the highest antioxidant ability with $\mathrm{IC}_{50}$ value of $48.2 \pm 2.9$ $\mu \mathrm{g} / \mathrm{mL}$ followed by stigmasterol and daucosterol (Figure 4). 


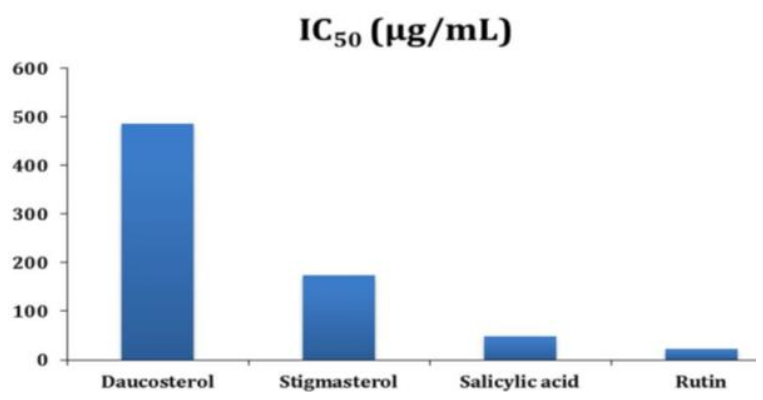

Figure 4. Antioxidant activity of isolated compounds.

\section{Conclusions}

Antioxidant, natural constituents were purified from the aerial parts of $P$. ferulacea. The chemical structure of the isolated metabolites was elucidated using spectroscopic techniques like NMR and FT-IR as well as elemental analysis. Daucosterol, stigmasterol, and salicylic acid were reported for the first time from the genus Prangos. Moreover, their radical scavenging activity was determined using DPPH assay. Findings showed that $P$. ferulacea contains natural steroids and their glycosides and could be considered for more phytochemical and pharmacological studies.

\section{Funding}

This research received no external funding.

\section{Acknowledgments}

This work was supported by Urmia University of Medical Sciences as a Pharm. D. thesis (No. $35)$.

\section{Conflicts of Interest}

The authors declare no conflict of interest.

\section{References}

1. Mottaghipisheh, J.; Kiss, T.; Tóth, B.Csupor, D. The Prangos genus: A comprehensive review on traditional use, phytochemistry, and pharmacological activities. Phytochem Rev 2020, https://doi.org/10.1007/s11101020-09688-3.

2. Bagherifar, S.; Sourestani, M.M.; Zolfaghari, M.; Mottaghipisheh, J.; Zomborszki, Z. P.Csupor, D. Chemodiversity of Volatile Oil Contents of Various Parts of 10 Iranian Prangos ferulacea Accessions, With Analysis of Antiradical Potential. Nat Prod Commun 2019, 14, 1-9, https://doi.org/10.1177/1934578X19851985.

3. Geidarov, I.G.; Serkerov, S.V. Coumarins from Roots of Prangos biebersteinii. Chem Nat Compd 2016, 52 , 700-701, https://doi.org/10.1007/s10600-016-1746-9.

4. Gholivand, M.B.; Yamini, Y.; Dayeni, M.; Shokoohinia, Y. The influence of the extraction mode on three coumarin compounds yield from Prangos ferulacea (L.) Lindl roots. J Iran Chem Soc 2015, 12, 707-714, https://doi.org/10.1007/s13738-014-0529-0.

5. Bruno, M.; Ilardi, V.; Lupidi, G.; Quassinti, L.; Bramucci, M.; Fiorini, D.; Venditti, A.Maggi, F. Composition and biological activities of the essential oil from a Sicilian accession of Prangos ferulacea (L.) Lindl. Nat Prod Res 2019, 1-11, https://doi.org/10.1080/14786419.2019.1598996.

6. Razavi, S.M.; Nazemiyeh, H.; Zarrini, G.; Asna-Asharii, S.; Dehghan, G. Chemical composition and antimicrobial activity of essential oil of Prangos ferulaceae (L.) Lindl from Iran. Nat Prod Res 2010, 24, 530-533, https://doi.org/10.1080/14786410802379539.

7. Razavi, S.M.; Nazemiyeh, H.; Hajiboland, R.; Kumarasamy, Y.; Delazar, A.; Nahar, L.; Sarker, S.D. Coumarins from the aerial parts of Prangos uloptera (Apiaceae). Rev Bras Farmacogn 2008, 18, 1-5, https://doi.org/10.1590/S0102-695X2008000100002 . 
8. Khoury, M.; El Beyrouthy, M.; Eparvier, V.; Ouaini, N.; Stien, D. Chemical diversity and antimicrobial activity of the essential oils of four Apiaceae species growing wild in Lebanon. J Essent Oil Res 2018, 30, 25-31, https://doi.org/10.1080/10412905.2017.1372314.

9. Shokoohinia, Y.; Sajjadi, S.-E.; Gholamzadeh, S.; Fattahi, A.; Behbahani, M. Antiviral and cytotoxic evaluation of coumarins from Prangos ferulacea. Pharm Biol 2014, 52, 1543-1549, https://doi.org/10.3109/13880209.2014.907322.

10. Numonov, S.; Sharopov, F.S.; Atolikhshoeva, S.; Safomuddin, A.; Bakri, M.; Setzer, W.N.; Musoev, A.; Sharofova, M.; Habasi, M.; Aisa, H.A. Volatile Secondary Metabolites with Potent Antidiabetic Activity from the Roots of Prangos pabularia Lindl.-Computational and Experimental Investigations. Appl Sci 2019, 9, 2362-2378, https://doi.org/10.3390/app9112362.

11. Razavi, S.M.; Zarrini, G.; Zahri, S.; Mohammadi, S. Biological activity of Prangos uloptera DC. roots, a medicinal plant from Iran. Nat Prod Res 2010, 24, 797-803, https://doi.org/10.1080/14786410802588667.

12. Mahmoudi Kordi, F.; Valizadeh, H.; Hosseinzadeh, Z.; Bahadori, M.B. Furocoumarins from Heracleum rawianum in Iran. Iran Chem Commun 2015, 3, 1-5.

13. Numonov, S.; Bobakulov, K.; Numonova, M.; Sharopov, F.; Setzer, W.N.; Khalilov, Q.; Begmatov, N.; Habasi, M.; Aisa, H.A. New coumarin from the roots of Prangos pabularia. Nat Prod Res 2018, 32, 23252332, https://doi.org/10.1080/14786419.2017.1413558.

14. Bahadori, M.B.; Zengin, G.; Bahadori, S.; Maggi, F.; Dinparast, L. Chemical composition of essential oil, antioxidant, antidiabetic, anti-obesity, and neuroprotective properties of Prangos gaubae. Nat Prod Commun 2017, 12, 1945-1948, https://doi.org/10.1177/1934578X1701201233.

15. Özek, G.; Bedir, E.; Tabanca, N.; Ali, A.; Khan, I.A.; Duran, A.; Başer, K.H.; Özek, T. Isolation of eudesmane type sesquiterpene ketone from Prangos heyniae H. Duman \& MF Watson essential oil and mosquitocidal activity of the essential oils. Open Chem 2018, 16, 453-467, https://doi.org/10.1515/chem2018-0051.

16. Mamadalieva, N. Z.; Abdullaeva, N. S.; Rosenau, T.; Fakhrutdinova, M.; Azimova, S. S.Böhmdorfer, S. Composition of essential oils from four Apiaceae and Asteraceae species growing in Uzbekistan. Nat Prod Res 2018, 32, 1118-1122, https://doi.org/10.1080/14786419.2017.1375928.

17. Sonboli, A.; Bahadori, M. B.; Dehghan, H.; Aarabi, L.; Savehdroudi, P.; Nekuei, M.; Pournaghi, N.; Mirzania, F. Chemotaxonomic Importance of the Essential-Oil Composition in Two Subspecies of Teucrium stocksianum Boiss. from Iran. Chem Biodivers 2013, 10, 687-694.

18. Yousefi, K.; Hamedeyazdan, S.; Hodaei, D.; Lotfipour, F.; Baradaran, B.; Orangi, M.; Fathiazad, F. An in vitro ethnopharmacological study on Prangos ferulacea: a wound healing agent. BioImpacts: BI 2017, 7, 75-82, https://doi.org/10.15171/bi.2017.10.

19. Asghari, B.; Mafakheri, S.; Zarrabi, M.; Erdem, S.; Orhan, I.; Bahadori, M. Therapeutic target enzymes inhibitory potential, antioxidant activity, and rosmarinic acid content of Echium amoenum. S Afr J Bot 2019, 120, 191-197, https://doi.org/10.1016/j.sajb.2018.05.017.

20. Dinparast, L.; Hemmati, S.; Zengin, G.; Alizadeh, A.A.; Bahadori, M.B.; Kafil, H.S.Dastmalchi, S. Rapid, Efficient, and Green Synthesis of Coumarin Derivatives via Knoevenagel Condensation and Investigating Their Biological Effects. ChemistrySelect 2019, 4, 9211-9215, https://doi.org/10.1002/slct.201901921.

21. Asghari, B.; Zengin, G.; Bahadori, M.B.; Abbas-Mohammadi, M.; Dinparast, L. Amylase, glucosidase, tyrosinase, and cholinesterases inhibitory, antioxidant effects, and GC-MS analysis of wild mint (Mentha longifolia var. calliantha) essential oil: a natural remedy. Eur J Integr Med 2018, 22, 44-49, https://doi.org/10.1016/j.eujim.2018.08.004.

22. Bahadori, M.B.; Kirkan, B.; Sarikurkcu, C.; Ceylan, O. Metabolite profiling and health benefits of Stachys cretica subsp. mersinaea as a medicinal food. Ind Crops Prod 2019, 131, 85-89, https://doi.org/10.1016/j.indcrop.2019.01.038.

23. Valizadeh, H.; Mahmoodi, K.; Alizadeh, Z.; Bahadori, M. Isolation and structure elucidation of secondary metabolites from Echinophora platyloba DC from Iran. J Med Plants 2014, 1, 15-21.

24. Bahadori, M.B.; Dinparast, L.; Valizadeh, H.; Farimani, M.M.; Ebrahimi, S.N. Bioactive constituents from roots of Salvia syriaca L.: Acetylcholinesterase inhibitory activity and molecular docking studies. S Afr J Bot 2016, 106, 1-4, https://doi.org/10.1016/j.sajb.2015.12.003.

25. Singh, K.S.; Sawant, S.G.; Devi, P.; Kaminsky, W. Stigmasterol from Eichhornia crassipes (Water Hyacinth): Isolation, Characterization and X-ray Structure. Asian J Chem 2015, 27, https://doi.org/10.14233/ajchem.2015.18832.

26. Gade, S.; Rajamanikyam, M.; Vadlapudi, V.; Nukala, K.M.; Aluvala, R.; Giddigari, C.; Karanam, N.J.; Barua, N. C.; Pandey, R.; Upadhyayula, V.S.V. Acetylcholinesterase inhibitory activity of stigmasterol \& hexacosanol is responsible for larvicidal and repellent properties of Chromolaena odorata. Biochimica et Biophysica Acta (BBA)-General Subjects https://doi.org/10.1016/j.bbagen.2016.11.044.

27. Kangsamaksin, T.; Chaithongyot, S.; Wootthichairangsan, C.; Hanchaina, R.; Tangshewinsirikul, C.; Svasti, J. Lupeol and stigmasterol suppress tumor angiogenesis and inhibit cholangiocarcinoma growth in mice via downregulation of tumor necrosis factor- $\alpha$. PLoS One 2017, 12, 1-16, https://doi.org/10.1371/journal.pone.0189628. 
28. Arif, T. Salicylic acid as a peeling agent: a comprehensive review. Clinical, cosmetic and investigational dermatology 2015, 8, 455-461, https://doi.org/10.2147/CCID.S84765.

29. Bahadori, M.B.; Zengin, G.; Bahadori, S.; Maggi, F.; Dinparast, L. Chemical composition of essential oil, antioxidant, antidiabetic, anti-obesity, and neuroprotective properties of Prangos gaubae. Nat Prod Commun 2017, 12, 1945-1948, https://doi.org/10.1177/1934578X1701201233. 